\title{
Mouse forkhead L2 maintains repression of FSH-dependent genes in the granulosa cell
}

\author{
Fang-Ting Kuo ${ }^{1}$, Kenneth Fan ${ }^{1}$, Ikuko Bentsi-Barnes ${ }^{1}$, Gillian M Barlow ${ }^{1}$ \\ and Margareta D Pisarska ${ }^{1,2}$ \\ ${ }^{1}$ Division of Reproductive Endocrinology and Infertility, Department of Obstetrics/Gynecology, Center for Fertility and \\ Reproductive Medicine, Cedars-Sinai Medical Center, 8635 West Third Street, Suite 160W, Los Angeles, California \\ 90048, USA and ${ }^{2}$ David Geffen School of Medicine, UCLA, Los Angeles, California 90095, USA
}

Correspondence should be addressed to M D Pisarska at Division of Reproductive Endocrinology and Infertility, Department of Obstetrics/Gynecology, Center for Fertility and Reproductive Medicine, Cedars-Sinai Medical Center; Email: pisarskam@Cshs.org

\begin{abstract}
The forkhead transcription factor forkhead box L2 (FOXL2) is expressed in granulosa cells of small and medium follicles in the mouse ovary. FoxI2 female knockout mice exhibit primordial follicle depletion and primary ovarian failure, but evidence from adult female conditional FoxI2 knockout mice suggests that FOXL2 may also play a significant role in maintenance of ovarian differentiation at stages beyond the primordial follicle and initial wave of folliculogenesis. We previously showed that human FOXL2 functions as a transcriptional repressor of several key genes involved in granulosa cell proliferation and differentiation, including steroidogenic acute regulatory protein (STAR), P450aromatase (CYP19A1 (CYP19)), P450scc (CYP11A1 (CYP11A)), and cyclin D2 (CCND2). To elucidate the role of mouse FOXL2, we determined its role in transcriptional regulation in Chinese hamster ovary $(\mathrm{CHO})$ cells and then confirmed our findings in mouse granulosa cells. We found that mouse FOXL2 represses the activities of the mouse Star, Cyp19a1, Cyp11a1 promoters in CHO cells, but may not repress the Ccnd2 promoter, and identified the minimal mouse Star, Cyp19a1, and Cyp11a1 promoter regions responsive to FOXL2 regulation. We then knocked down Fox/2 in mouse granulosa cells using siRNA, which resulted in significantly increased expression levels of mouse Star, Cyp19a1, and Cyp11a1 but not Ccnd2. To increase Foxl2 expression levels, we generated a mouse Foxl2 lentiviral construct and used it to infect mouse granulosa cells. Following lentiviral infection, the expression levels of mouse Star, Cyp19a1, and Cyp11a1, but not Ccnd2, decreased significantly. These data confirm that mouse FOXL2 functions as a transcriptional repressor of key granulosa cell genes that influence ovarian development.

Reproduction (2012) 144 485-494
\end{abstract}

\section{Introduction}

The forkhead family of transcription factors plays a significant role in proliferation and differentiation (Brissette et al. 1996, Dottori et al. 2001, Nakae et al. 2003, Park et al. 2005, Pisarska et al. 2011). Members contain a characteristic winged helix DNA binding domain but have divergent transactivation or transrepression domains (Kaufmann \& Knochel 1996, Kaestner et al. 2000, Carlsson \& Mahlapuu 2002, Lehmann et al. 2003). A number of forkhead family members that function as transcriptional repressors act to regulate tissue differentiation in a spatiotemporal manner (Brissette et al. 1996, Zhou et al. 1997, Blixt et al. 2000, Nakae et al. 2003). One such member, forkhead box L2 (FOXL2), may function as a determinant of differentiation throughout the lifetime of the female gonad. This may be achieved as early as germ cell fate, through FOXL2's activity as a repressor of the catabolic cytochrome P450 enzyme, CYP26B1, which is involved in degradation of retinoic acid regulating germ cell fate and subsequent sexual differentiation (Kashimada et al. 2011). Tissue differentiation during ovarian development is also regulated by FOXL2, and complete loss of Foxl2 expression leads to an immediate loss of the primordial (type 2) follicle pool (Crisponi et al. 2001, Schmidt et al. 2004, Uda et al. 2004). Histological studies indicate that Fox/2 is expressed in the undifferentiated granulosa cells of small (type 3a) and medium (types $3 \mathrm{~b}, 4$, and $5 \mathrm{a}$ ) follicles in the ovary, past the timepoint when primordial follicle depletion occurs in Foxl2 knockout mice (Crisponi et al. 2001, Schmidt et al. 2004, Uda et al. 2004), and evidence from adult female conditional Foxl2 knockout mice suggests that FOXL2 may also play a significant role in maintenance of ovarian differentiation (Uhlenhaut et al. 2009). However, these studies are limited and a better understanding of FOXL2 in all stages of follicle development is necessary in order to understand the role of FOXL2 in follicle maintenance. In humans, 
heterozygous mutations in the FOXL2 gene lead to blepharophimosis-ptosis-epicanthus inversus syndrome (BPES), which is associated with characteristic eyelid dysplasia, premature ovarian failure, and infertility in females (Zlotogora et al. 1983). Unlike the primary ovarian failure from primordial follicle arrest that occurs in Foxl2 homozygous knockout mice (Schmidt et al. 2004, Uda et al. 2004), humans with BPES and heterozygous mutations undergo a complete sequence of follicle development with early depletion of the follicle pool and premature ovarian failure (Fraser et al. 1988, Schmidt et al. 2004).

FSH is necessary for maturation of ovarian follicles (Kumar et al. 1997). This process is regulated through the G-protein-coupled FSH receptor, which activates adenylyl cyclase, increases cAMP production, and activation of protein kinase A (Richards 1994, Richards et al. 1998, Richards \& Pangas 2010). This and other signaling cascades involving PI3K (Wayne et al. 2007), RAS (Wayne et al. 2007), and glycogen synthase kinase $3 \beta$ (GSK3 $\beta$ ) (Gonzalez-Robayna et al. 2000) regulate transcription factors that in turn influence granulosa cell proliferation and differentiation (Hsueh et al. 1984). Although some transcription factors function as activators under the influence of $\mathrm{FSH}$, including $\beta$-catenin (CTNNB1; Fan et al. 2010), others, including members of the forkhead family, act as negative regulators (Park et al. 2005, Liu et al. 2009). In studies performed using Chinese hamster ovary $(\mathrm{CHO})$ cells, we previously demonstrated that human FOXL2 functions as a transcriptional repressor of several key genes involved in granulosa cell proliferation and differentiation. These include the human steroidogenic acute regulatory protein (STAR) gene (Pisarska et al. 2004), which translocates cholesterol from the outer to the inner membrane of mitochondria, the rate-limiting step in steroidogenesis (Clark et al. 1994, Lin et al. 1995, Stocco 2001); human P450aromatase (CYP19A1 (CYP19); Bentsi-Barnes et al. 2010, Kuo et al. 2011), which is a key enzyme expressed in granulosa cells and is the ratelimiting step in the conversion of androgens to estrogens; and human P450scc (CYP11A1 (CYP1 1A); Bentsi-Barnes et al. 2010, Kuo et al. 2011), which cleaves the side chain of cholesterol to produce pregnenolone, the first committed and rate-limiting step in steroid hormone synthesis (Stocco 2001). We found that human FOXL2 also represses transcription of cyclin D2 (CCND2; Bentsi-Barnes et al. 2010, Kuo et al. 2011), which regulates cyclin-dependent kinases 4 or $6(\mathrm{Cdk} 4$ or Cdk6) to control G1 phase progression of the cell cycle and is involved in granulosa cell proliferation (Sicinski et al. 1996, Moons et al. 2002). These data suggested that FOXL2 may function as a suppressor of ovarian follicle progression in small and medium follicles by the prevention of premature differentiation and/or proliferation of granulosa cells. However, testing this hypothesis in a human system is limited by lack of access to human granulosa cells other than cell lines derived from granulosa cell tumors, such as the KGN cell line (Nishi et al. 2001), which contains a C402G mutation in FOXL2 (Shah et al. 2009). To determine whether mouse FOXL2 functions similarly to human FOXL2, and the utility of mouse granulosa cells as a model system, we cloned the mouse Fox/2 cDNA and determined its role in the regulation of the mouse Star, Cyp19a1, Cyp11a1, and $C$ cnd 2 genes under the influence of FSH in mouse granulosa cells.

\section{Results}

\section{Mouse Star, Cyp19a1, and Cyp11a1 promoters, but not the Cond2 promoter, are repressed by mouse FOXL2}

We have previously demonstrated that human FOXL2 represses transcription of the human STAR, CYP19A1, CYP11A1, and CCND2 promoters (Pisarska et al. 2004, Bentsi-Barnes et al. 2009, Kuo et al. 2011). To determine whether mouse FOXL2 functions in a similar manner to human FOXL2, the -192 bp mouse Star, -341 bp mouse Cyp19a1, - 862 bp mouse Cyp11a1, and -1142 to -248 bp mouse Ccnd2 promoter fragments were cloned into a luciferase reporter vector. These promoterluciferase constructs were co-transfected into $\mathrm{CHO}$ cells with increasing amounts of the mouse Fox/2 expression vector, and the resulting luciferase activities were measured after $24 \mathrm{~h}$ of transfection. In the presence of mouse FOXL2, the basal activities of the mouse Star, Cyp19a1, and Cyp11a1 promoters were repressed even at the lowest concentration of FOXL2 (Fig. 1A, B and C), whereas the mouse $C c n d 2$ promoter was only modestly repressed (Fig. 1D). These results indicate that mouse FOXL2 functions as a transcriptional repressor and represses the activities of the mouse Star, Cyp19a1, and Cyp11a1 promoters and possibly the mouse Ccnd 2 promoter.

\section{Minimal regions of the mouse Star, Cyp19a1, and Cyp11a1 promoters responsive to repression by mouse FOXL2}

To determine the minimal regions of these promoters responsive to regulation by FOXL2, we generated a series of luciferase reporter constructs as follows: two mouse Star promoter fragments (from -192 and $-100 \mathrm{bp}$ ), two mouse Cyp19a1 promoter fragments (from -341 and $-58 \mathrm{bp}$ ), three mouse Cyp11a1 promoter fragments (from $-862,-622$, and $-182 \mathrm{bp}$ ), and two mouse Ccnd2 promoter fragments (from -1142 to $-248 \mathrm{bp}$ and -316 to $-248 \mathrm{bp}$ ). Each of these promoterluciferase constructs was transiently co-transfected with the mouse FOXL2 expression construct into $\mathrm{CHO}$ cells, and the resulting luciferase activities were measured $24 \mathrm{~h}$ after transfection. We found that mouse FOXL2 continued to function as a transcriptional repressor of the 

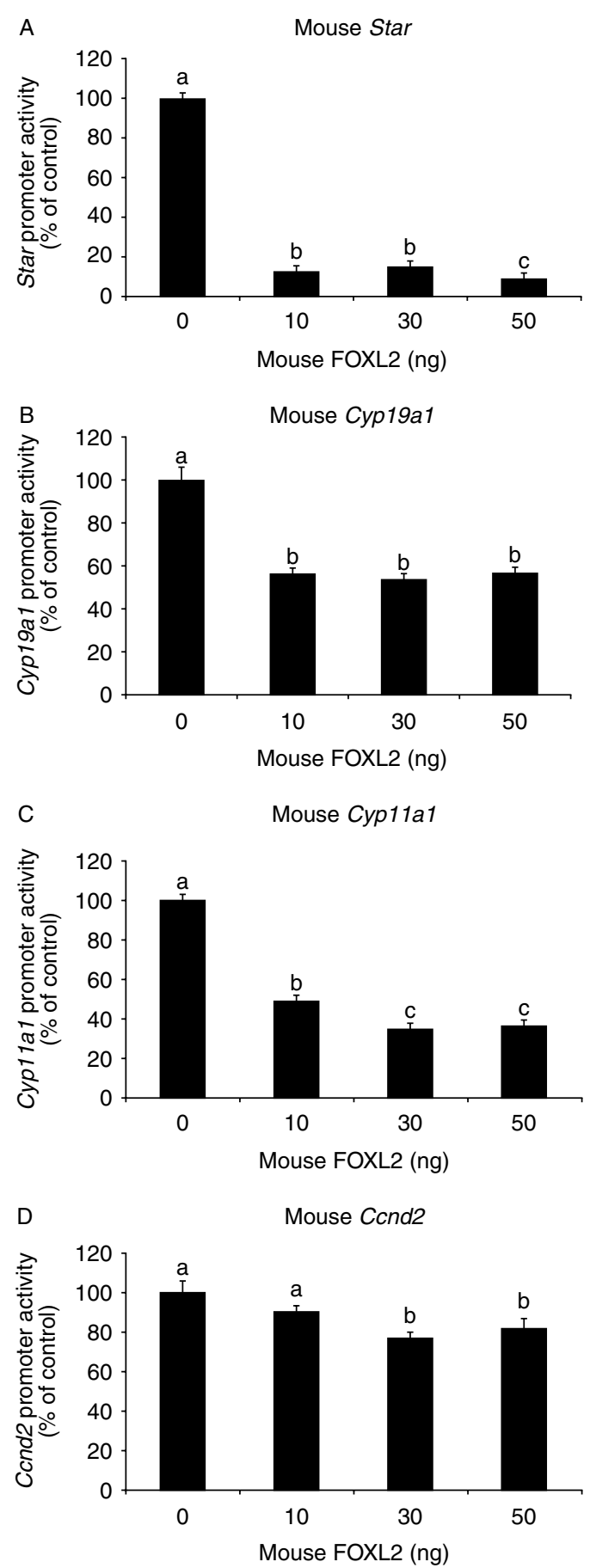

Figure 1 Mouse Star, Cyp19a1, and Cyp11a1 promoters are repressed by mouse FOXL2. CHO cells were transiently transfected with mouse wild-type FOXL2 and reporter constructs for the mouse Star (A), Cyp19a1 (B), Cyp11a1 (C), or Ccnd2 (D) promoters. The normalized luciferase activity of each sample was compared with the normalized luciferase activity of cells transfected with the pGL2-basic expression vector. Values shown are expressed as percentage (\%) of control. One-way ANOVA was performed between samples and different letters $(\mathrm{a}, \mathrm{b}$, or $\mathrm{c})$ denote significant differences $(P<0.05)$ between samples. In the presence of mouse FOXL2, the basal activities of the mouse Star, Cyp19a1, and Cyp11a1 promoters were repressed (A, B and C), but minimal effect was seen on the mouse $C$ Cnd2 (D) promoter. shortest Star (Fig. 2A), Cyp19a1 (Fig. 2B), and Cyp11a1 promoter fragments (Fig. 2C) but failed to consistently repress transcription of the $C \mathrm{c}$ d 2 promoter fragments (Fig. 2D). These results suggest that binding sites for mouse FOXL2 are located in the $-100,-58$, and -182 bp regions of the mouse Star, Cyp19a1, and Cyp11a1 promoters respectively.

\section{Knockdown of FOXL2 in mouse granulosa cells increases the expression of Star, Cyp19a1, and Cyp11a1}

To test whether mouse FOXL2 also functions as a transcriptional repressor of the Star, Cyp19a1, Cyp11a1, and $C$ cnd 2 genes in granulosa cells, we used siRNA to knock down the expression of Fox/2 in primary mouse granulosa cells and then treated the cells with either FSH and testosterone or FSH alone. Testosterone was included to better mimic the environment in the two-cell model of ovarian follicles, where testosterone released from theca cells may serve as a substrate for P450aromatase (the product of the Cyp19a1 gene) in the conversion of androgens to estrogens in granulosa cells (Liu \& Hsueh 1986), and to enhance Cyp19a1 expression. As shown in Fig. 3A, these primary mouse granulosa cell cultures expressed Foxl2, and following transfection with a FoxI2 siRNA and treatment with FSH and testosterone, the expression level of mouse Fox 2 was reduced to $30 \%$ vs the level in cells transfected with non-silencing siRNA. Slightly less reduction in the expression level of mouse Fox/2 was observed when transfected cells were treated with $\mathrm{FSH}$ alone (Fig. 3B). We then compared the expression levels of Star, Cyp19a1, Cyp11a1, and Ccnd2 in granulosa cells transfected with Fox/2 siRNA vs a non-silencing siRNA, using quantitative real-time PCR (q-RT-PCR). As shown in Fig. 3C, transfection with the FoxI2 siRNA and treatment with FSH and testosterone resulted in significantly increased expression levels of the mouse Star (2.5-fold, $P<0.005)$, Cyp19a1 (fourfold, $P<0.005)$, and Cyp11a1 (1.5-fold, $P<0.005)$ genes but had no effect on the expression level of $C c n d 2(P>0.1)$. When cells were transfected with the FoxI2 siRNA and treated with $\mathrm{FSH}$ alone, similar results were obtained: significant increases occurred in the expression levels of the mouse Star, Cyp19a1, and Cyp11a1 genes, but no effect was seen on the expression level of mouse $C c n d 2$ (Fig. 3D). These findings are consistent with the $\mathrm{CHO}$ cell model and support a role for FOXL2 as a transcriptional repressor of Star, Cyp19a1, and Cyp11a1, but not Ccnd2, in mouse granulosa cells.

\section{Overexpression of FOXL2 in mouse granulosa cells decreases the expression of Star, Cyp19a1, and Cyp11a1}

To further confirm that mouse FOXL2 negatively regulates expression of the mouse Star, Cyp19a1, and Cyp11a1 genes, we generated a lentiviral vector for 

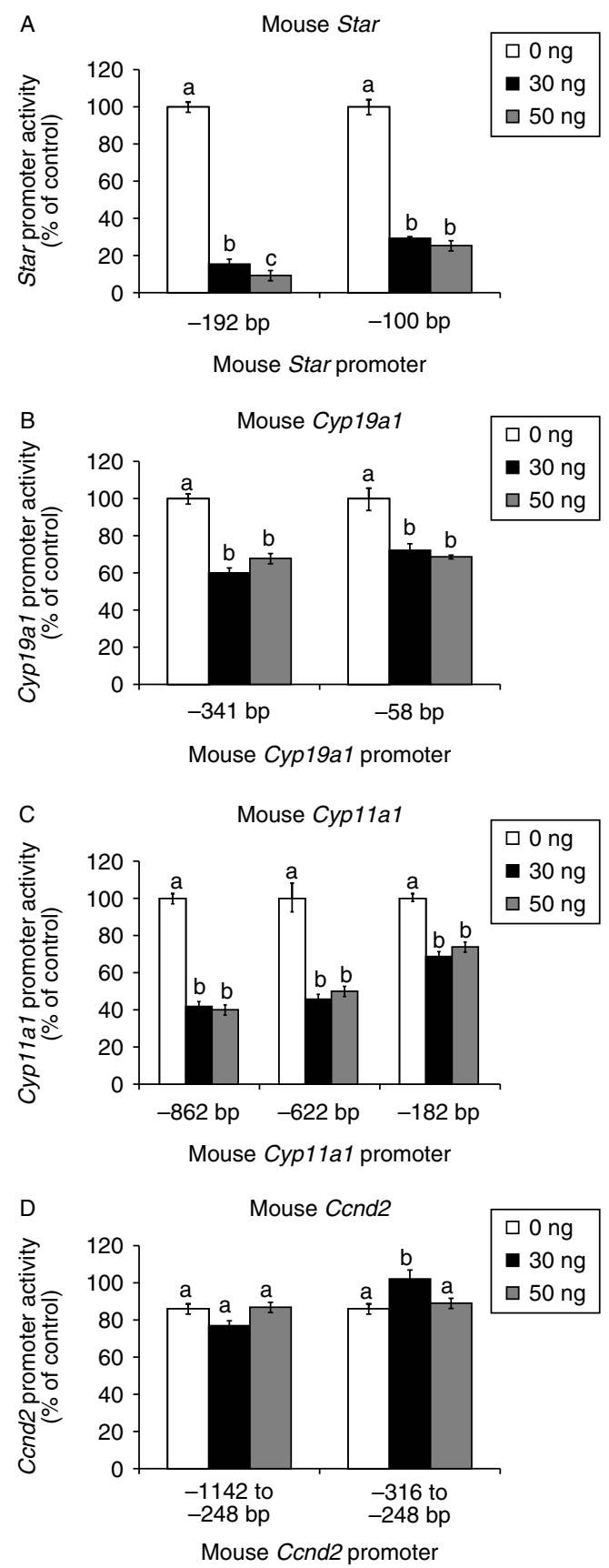

Figure 2 Minimal promoter regions responsive to repression by mouse FOXL2. A series of luciferase reporter constructs containing fragments of the mouse Star, Cyp19a1, Cyp11a1, and Ccnd2 promoters was generated. Each of these promoter-luciferase constructs was transiently co-transfected with mouse FOXL2 into $\mathrm{CHO}$ cells, and the resulting luciferase activities were measured $24 \mathrm{~h}$ after transfection. The normalized luciferase activity of each sample was compared with the normalized luciferase activity of cells transfected with the pGL2-basic expression vector. Values shown are expressed as percentage of control. One-way ANOVA was performed between samples, and different letters $(\mathrm{a}, \mathrm{b}$, or $\mathrm{c})$ denote significant differences $(P<0.05)$ between samples. FOXL2 continues to function as a transcriptional repressor of the shortest Star (A), Cyp19a1 (B), and Cyp11a1 promoter fragments (C). In contrast, FOXL2 fails to repress transcription of the Ccnd2 promoter (D). mouse FOXL2 and used this to infect primary mouse granulosa cell cultures. The cells were then treated with FSH and testosterone or FSH alone, as described earlier. As shown in Fig. 4A, when mouse granulosa cells were infected with the mouse Fox/2 lentivirus and treated with FSH and testosterone, the expression level of Foxl 2 was increased up to 17 -fold vs that seen in cells infected with an empty lentiviral vector backbone. Similar results were obtained when cells were infected with the mouse Fox/2 lentivirus and treated with FSH alone (Fig. 4B). We then compared the expression of the mouse Star, Cyp19a1, Cyp11a1, and Ccnd2 genes in granulosa cells infected with the mouse Fox/2 lentiviral vector vs lentiviral vector backbone. As shown in Fig. 4C, infection with the FoxI2 lentivirus followed by treatment with FSH and testosterone resulted in significantly decreased expression of the mouse Star, Cyp19a1, and Cyp11a1 genes $(P<0.05)$ but had no significant effect on the expression of Ccnd2 $(P>0.05)$. Similar results were obtained when infected cells were treated with FSH alone, with the exception of an increase in the repression of $C \mathrm{cnd} 2$, such that the effect of Foxl2 now reached significance $(P<0.05$, Fig. 4D). These data suggest that increased expression of mouse Foxl 2 further decreases the expression of Star, Cyp19a1, and Cyp11a1 in mouse granulosa cells, again supporting a role for FOXL2 as a transcriptional repressor of these genes in mouse granulosa cells and confirming our studies conducted in the $\mathrm{CHO}$ cell line.

\section{Discussion}

Understanding the genes and pathways controlling granulosa cell steroidogenesis, proliferation, and differentiation is of central importance in understanding normal ovarian folliculogenesis. We have previously shown that Fox 2 is predominantly expressed in the granulosa cells of small (type 3a) and medium (types 3b, 4 , and $5 \mathrm{a}$ ) follicles in the mouse ovary but is absent from the granulosa cells of large antral follicles (types 7 and 8) and the corpus luteum (Pisarska et al. 2004). Our current results indicate that mouse FOXL2 represses the activities of the Star, Cyp19a1, and Cyp11a1 promoters in $\mathrm{CHO}$ cells, and this is confirmed in mouse granulosa cells in both knockdown and upregulation studies following treatment with $\mathrm{FSH}$ and testosterone or $\mathrm{FSH}$ alone. Follicular maturation to a preovulatory phenotype is dependent on FSH (Kumar et al. 1997) leading to expression of key genes including Cyp19a1 and Cyp11a1 (Hsueh et al. 1984). We previously showed that in the presence of human FOXL2, the transcriptional activities of human StAR (Pisarska et al. 2004), human P450aromatase (CYP19A1), and human P450scC (CYP11A1) (Bentsi-Barnes et al. 2010, Kuo et al. 2011), markers of granulosa cell functional maturation, are repressed. Based on these results and the premature ovarian failure phenotypes seen in humans with heterozygous mutations in FOXL2 and BPES, we have 
hypothesized that relief of this transcriptional repression may be required to allow granulosa cell differentiation and follicle maturation. Our present results for mouse FOXL2 are consistent with our previous human findings, further supporting our hypothesis that FOXL2 may influence follicle maturation by preventing the
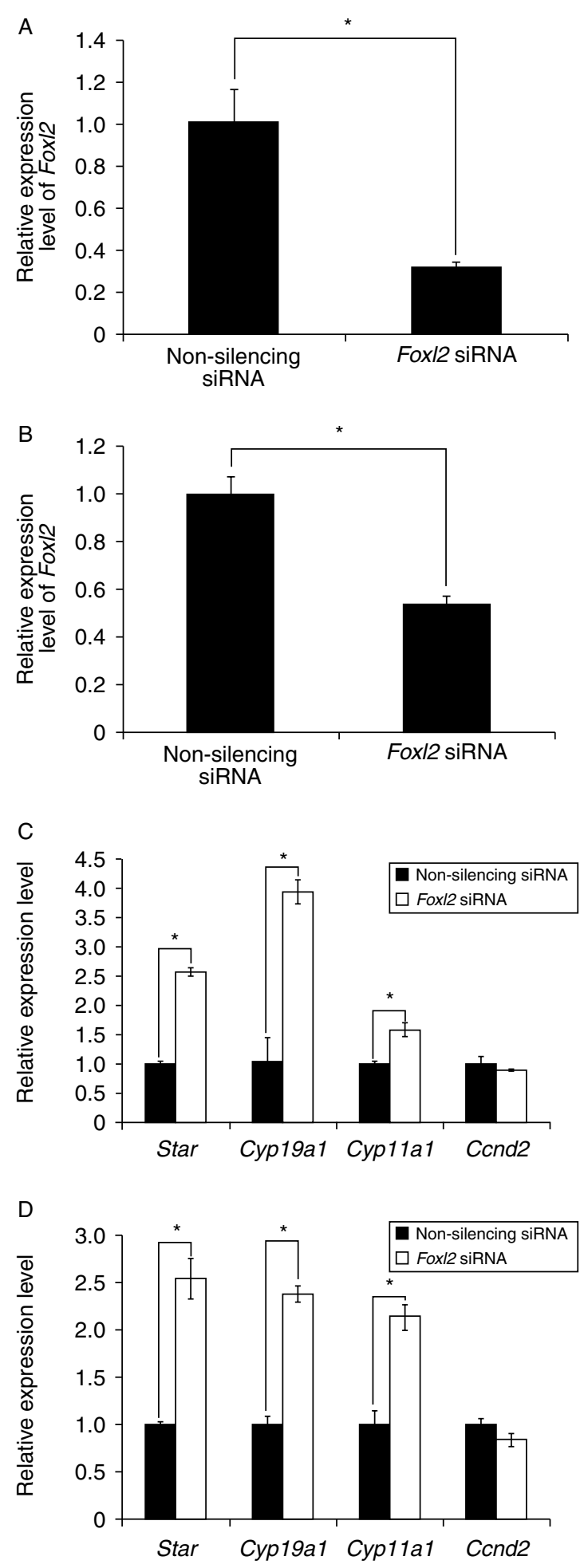

premature differentiation of granulosa cells, and thus suppress ovarian follicle progression.

Testosterone was included with $\mathrm{FSH}$ in these experiments because in ovarian follicles in vivo, testosterone released from theca cells may serve as a substrate for P450aromatase (the product of the Cyp19a1 gene) in the conversion of androgens to estrogens in granulosa cells (Liu \& Hsueh 1986). Testosterone may also enhance expression of Cyp19a1 in granulosa cells (Fitzpatrick \& Richards 1991). Therefore, we included testosterone to better mimic the environment in the two-cell model of ovarian follicles, with theca cells surrounding granulosa cells, and controlled for independent effects of testosterone by repeating the experiments using $\mathrm{FSH}$ alone. Overall, we did not find significant differences in the effects on Star, Cyp19a1, and Cyp11a1 when Foxl2 was overexpressed in the presence of $\mathrm{FSH}$ and testosterone vs FSH alone. Further, the effects on Star, Cyp19a1, and Cyp11a1 or Ccnd2 were also not significantly different when Fox/2 expression was knocked down in the presence of $\mathrm{FSH}$ and testosterone vs $\mathrm{FSH}$ alone, although the expression of Cyp19a1 in the absence of FOXL2 repression is greater in the presence of $\mathrm{FSH}$ and testosterone than for FSH alone, likely because testosterone can enhance Cyp19a1 expression.

We found that mouse FOXL2 does not appear to regulate the activity of the $\mathrm{C}$ cnd2 promoter in $\mathrm{CHO}$ cells, or the expression of $\mathrm{Ccnd} 2$ in mouse granulosa cells, with the exception that $C c n d 2$ expression is further repressed when Foxl2 is overexpressed in the presence of FSH alone, as opposed to FSH and testosterone. This may be due to differences in the consensus sites of these various promoters that are regulated by FOXL2. There have been a number of different FOXL2 binding sites described, the traditional forkhead consensus site $((\mathrm{G} / \mathrm{A})(\mathrm{T} / \mathrm{C})(\mathrm{A} / \mathrm{C}) \mathrm{AA}(\mathrm{C} / \mathrm{T}) \mathrm{A}$; Overdier et al. 1994, Pierrou et al. 1994, Kaufmann et al. 1995, Roux et al. 1995, Kaufmann \& Knochel 1996) and two nontraditional FOXL2 binding elements identified by Benayoun et al. (2008b) (GT(C/G)AAGG(G/T)) and Lamba et al. (2009) $(\mathrm{T}(\mathrm{A} / \mathrm{G} / \mathrm{T}) \mathrm{TT}(\mathrm{T} / \mathrm{G}) \mathrm{A}$; FOXL2 binding sites $\mathrm{A}$ and $\mathrm{B}$ in Fig. 5

Figure 3 Knock down of FOXL2 in mouse granulosa cells increases the expression of Star, Cyp19a1, and Cyp11a1. (A and B) Primary mouse granulosa cell cultures were transfected with a non-silencing siRNA or a Fox/2 siRNA and then treated with FSH and testosterone (A) or FSH alone (B). Fox/2 is endogenously expressed in these cultures, and following transfection with the Fox/2 siRNA, Fox/2 expression levels were reduced to $30-50 \%$ of those in cells transfected with nonsilencing siRNA. (C and D) Primary mouse granulosa cell cultures were transfected with a non-silencing siRNA or a Fox/2 siRNA and then treated with FSH and testosterone (C) or FSH alone (D). The expression levels of Star, Cyp19a1, Cyp11a1, and Ccnd2 in granulosa cells transfected with Fox/2 siRNA vs non-silencing siRNA were then compared using q-RT-PCR. Transfection with the Fox/2 siRNA resulted in significantly increased expression levels of the $\operatorname{Star}(P<0.005)$, Cyp19a1 $(P<0.005)$, and Cyp11a1 $(P<0.005)$ genes in mouse granulosa cells but had no effect on the expression level of mouse CCnd2 $(P>0.1) .{ }^{*}$ Indicates significant difference. Error bars indicate S.D. 
respectively). Interestingly, a steroidogenic factor-1 (SF-1) binding site ((T/C)CAAGG(T/C)C(A/G); Fig. 5, SF-1 binding site A; Ueda et al. 1992) shares sequence similar to the FOXL2 binding site identified by Benayoun et al. (2008b). Furthermore, SF1 binds to its own complimentary sequence ((T/C)G(G/A)CCTTG $(\mathrm{G} / \mathrm{A})$;
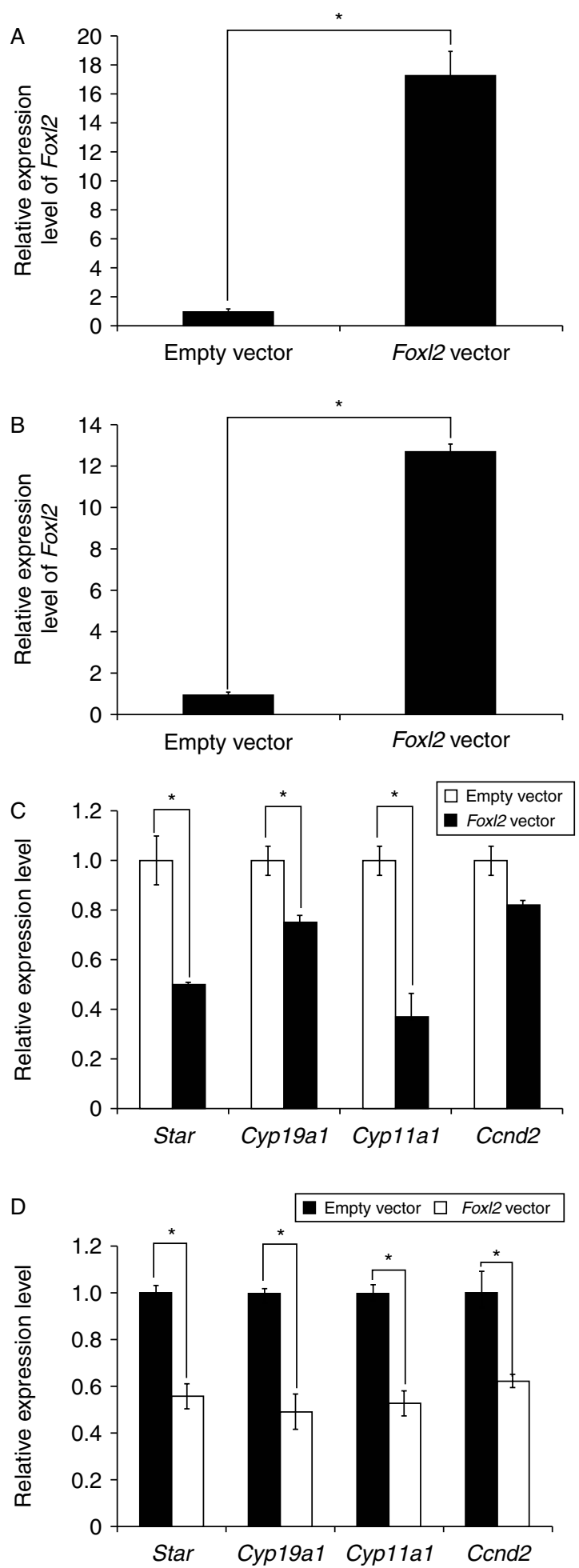

Fig. 5, SF-1 binding site B; Barnhart \& Mellon 1994). As shown in Fig. 5, the StAR promoter contains three FOXL2 binding sites $B$, one SF-1/FOXL2 binding site A, and one SF-1 binding site B; the Cyp19a1 promoter contains two FOXL2 binding sites $\mathrm{B}$ and one traditional forkhead binding site; and the Cyp11a1 promoter contains three SF-1/FOXL2 binding sites $A$, one FOXL2 binding site $\mathrm{B}$, and one $\mathrm{SF}-1$ binding site $\mathrm{B}$, whereas the Ccnd2 promoter only contains a single SF-1/FOXL2 binding site $\mathrm{A}$. As all the other promoters contain multiple FOXL2 and/or SF-1 binding sites, transcriptional regulation may be dependent, at least in part, on the number of binding sites present in a promoter. Furthermore, it may be the result of the interactions between FOXL2 and SF-1, as FOXL2 binding to SF-1 has been implicated in regulation of steroidogenic gene transcription: it has been associated with upregulation (Wang et al. 2007) and inhibition of transcriptional activation (Fleming et al. 2010, Park et al. 2010), whereas other studies have found that FOXL2 and SF-1 have completely opposing effects on gene regulation. As there is only one binding site in the Ccnd2 promoter tested (see Fig. 6), it is possible that FOXL2 and SF-1 compete for this site, leading to loss of transcriptional regulation.

In addition to SF-1, FOXL2 transcriptional regulation may be altered by other transcription factors known to bind to FOXL2 (Lee et al. 2005, Blount et al. 2009, Kim et al. 2009, Lamba etal. 2009), as well as FOXL2 binding to itself (Lamba et al. 2009, Benayoun et al. 2010, Fleming et al. 2010, Kuo et al. 2011). Further, posttranslational modifications such as sumoylation (Marongiu et al. 2010, Pisarska et al. 2010), phosphorylation (Benayoun et al. 2008a, Pisarska et al. 2010), and acetylation (Benayoun et al. 2008a) may all act to modify FOXL2 transcriptional activity under the influence of FSH and the various signaling cascades that have been identified in granulosa cell proliferation and differentiation. Further studies are

Figure 4 Overexpression of FOXL2 in mouse granulosa cells decreases the expression of Star, Cyp19a1, and Cyp11a1. (A and B) Primary mouse granulosa cell cultures were infected with a lentiviral vector for mouse FOXL2 or with an empty lentiviral vector backbone and then treated with $\mathrm{FSH}$ and testosterone (A) or FSH alone (B). After 5 days of infection, around $80 \%$ of the cells were GFP positive, indicating the MOI was around two. The expression levels of Fox/2 in granulosa cells infected with the mouse Fox/2 lentivirus were increased 13- to 17-fold vs those in cells infected with the lentiviral vector backbone. (C and D) The expression levels of Star, Cyp19a1, Cyp11a1, and Cond2 in granulosa cells infected with the mouse Fox/2 lentivirus vs the lentiviral vector backbone were then compared using q-RT-PCR. Infection with the Fox/2 lentivirus in the presence of FSH and testosterone resulted in significantly decreased expression of the mouse Star, Cyp19a1, and Cyp11a1 genes $(P<0.05)$ but had no significant effect on the expression of $C \mathrm{Cnd} 2(P>0.05)$. In the presence of FSH alone, infection with the Fox/2 lentivirus also resulted in significant decreased expression of the mouse Star, Cyp19a1, and Cyp11a1 genes $(P<0.05)$; however, there was increased repression of $C$ cnd2, which now reached significance $(P<0.05)$. ${ }^{*}$ Indicates significant difference. Error bars indicate S.D. 


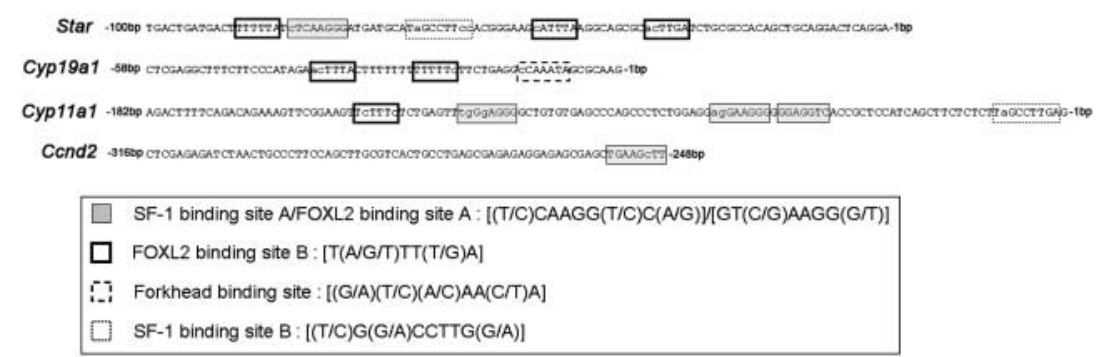

Figure 5 Comparison of the mouse and human CCND2 promoters. The promoters of mouse CCnd 2 and human $C C N D 2$ were analyzed and compared for SF-1 and FOXL2 binding sites. The mouse $C$ cnd 2 promoter contains a single SF1 binding site A/FOXL2 binding site A (denoted by a shaded box), whereas the human CCND2 promoter contains a single FOXL2 binding site B (denoted by a solid box). Base pair notations indicated are the positions relative to the transcriptional start sites for all sequences depicted.

necessary to identify the specific upstream regulators of FOXL2 transcriptional regulation.

Finally, we have demonstrated that $\mathrm{CHO}$ cells can be used as a model of FOXL2 regulation, as its activity as a transcriptional repressor in this system is similar to that in mouse granulosa cells. Although the Fox/2 knockout mouse has been instrumental in identifying its role as a determinant of tissue differentiation (Crisponi et al. 2001, Schmidt et al. 2004, Uda et al. 2004), the complete loss of the primordial follicle pool prevents study of Fox/2 in the adult ovary, where it is expressed in the undifferentiated granulosa cells of small and medium follicles, and may be a time when mutations of FOXL2 contribute to the premature ovarian failure phenotype in patients with BPES1. As human model systems to study FOXL2 in granulosa cells are limited, the use of mouse FOXL2 in granulosa cells as well as transfection studies in $\mathrm{CHO}$ cells may be suitable, based on our findings of similar transcriptional regulation of genes marking granulosa cell differentiation.

\section{Materials and Methods \\ Plasmids}

The mouse Fox/2 cDNA sequence (GenBank: NM 012020) was amplified from a mouse cDNA library by PCR and subcloned into the pcDNA3 vector using HindIII and Xbal restriction sites. The mouse Star promoter ( $-192 \mathrm{bp}$, the translation start site as +1 , sequence obtained from the UCSC Genome Browser), mouse P450aromatase (Cyp19a1) ovarian-specific promoter II (-341 bp, GenBank accession no. D67046), and mouse
P450scc (Cyp11a1) promoter ( -862 bp: GenBank accession no. J05511) were PCR amplified using genomic DNA as a template and Hotstar Taq polymerase (Qiagen) according to the manufacturer's protocol. The mouse cyclin D2 (Ccnd2) promoter $(-1142$ to $-248 \mathrm{bp})$ was kindly provided by Dr Martin Eilers (IMT University of Phillips, Marburg, Germany). Truncated promoter fragments for the mouse Star (spanning from -100 bp), Cyp19a1 (spanning from - 58 bp), Cyp11a1 (spanning from -622 and $-182 \mathrm{bp}$ ), and Cond2 (spanning from -316 to $-248 \mathrm{bp}$ ) promoters were also PCR amplified. PCR products for each of these promoter fragments were gel electrophoresed, and DNAs were extracted and subcloned into the pGL2 luciferase reporter vector backbone (Promega).

\section{Transfection and reporter assays}

$\mathrm{CHO}$ cells $\left(1 \times 10^{5} /\right.$ well in a 24 -well plate) were cultured in DMEM/F12 supplemented with 10\% FBS, 100 units $/ \mathrm{ml}$ penicillin, $100 \mu \mathrm{g} / \mathrm{ml}$ streptomycin, and $2 \mathrm{mM}$ glutamine. The following day, cells were transfected using Lipofectamine 2000 (Invitrogen) with the Star, Cyp19a1, Cyp11a1, or Cond2 promoter luciferase reporter vectors $(500 \mathrm{ng} /$ well) and the mouse Fox/2 expression construct (0-200 ng/well). The total DNA concentration in each well was maintained at $1 \mu \mathrm{g}$ by adding the empty pcDNA3 expression vector, including $50 \mathrm{ng}$ of indicator plasmid, pCMV- $\beta$-galactosidase. Twenty-four hours after transfection, luciferase activity was measured using a FLUOstar OPTIMA plate reader (BMG Labtech, Offenberg, Germany). Results were then normalized against $\beta$-galactosidase activity. The normalized luciferase activity of each sample was compared with the normalized luciferase activity of cells transfected with the pGL2-basic expression vector. Values shown are expressed as percentage of control.

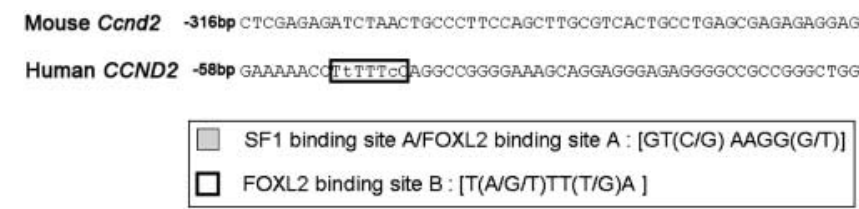

Figure 6 Analysis of FOXL2 DNA binding sites in the Star, Cyp19a1, Cyp11a1, and Ccnd2 promoters. The promoters of Star, Cyp19a1, Cyp11a1, and Ccnd2 were analyzed for SF-1 binding sites (A, ((T/C)CAAGG(T/C)C(A/G)); B, ((T/C)G(G/A)CCTTG(G/A))) and FOXL2 binding sites $(\mathrm{A},(\mathrm{GT}(\mathrm{C} / \mathrm{G}) \mathrm{AAGG}(\mathrm{G} / \mathrm{T})) ; \mathrm{B},(\mathrm{T}(\mathrm{A} / \mathrm{G} / \mathrm{T}) \mathrm{TT}(\mathrm{T} / \mathrm{G}) \mathrm{A})))$ as well as the consensus forkhead binding site $((\mathrm{G} / \mathrm{A})(\mathrm{T} / \mathrm{C})(\mathrm{A} / \mathrm{C}) \mathrm{AA}(\mathrm{C} / \mathrm{T}) \mathrm{A}))$. As SF1 binding site $\mathrm{A}$ and FOXL2 binding site A share the same core sequence CAAGGT, they are denoted by shaded boxes. FOXL2 binding site B is denoted by solid boxes, the consensus forkhead binding site is denoted by dashed boxes, and SF-1 binding site B is denoted by doted boxes. Base pair notation indicated is position relative to the transcriptional start site for all sequences depicted. 
Each condition was tested in quadruplicate, and each experiment was repeated at least three times.

\section{Primary mouse granulosa cell culture}

Ovaries were dissected from immature Swiss Webster outbred female mice at 23 days of age. The ovaries were rinsed using PBS and then incubated in separating medium (6.8 mM EGTA and $26 \mathrm{mM}$ sodium bicarbonate in DMEM/F12) for $10 \mathrm{~min}$. The ovaries were then placed in washing medium $(0.5 \mathrm{M}$ sucrose in DMEM/F12) for $5 \mathrm{~min}$ and then moved to culture medium (10\% FBS, 100 units $/ \mathrm{ml}$ penicillin, $100 \mu \mathrm{g} / \mathrm{ml}$ streptomycin, and $2 \mathrm{mM}$ glutamine in DMEM/F12). Mouse granulosa cells were obtained by puncturing the follicles with 25 gauge needles. The granulosa cells were collected and washed with culture medium, after which they were ready for primary cell culture.

\section{SiRNA transfection}

Mouse granulosa cells $\left(8 \times 10^{5} /\right.$ well in a six-well plate $)$ were plated shortly before transfection and incubated at $37^{\circ} \mathrm{C}$ with $5 \% \mathrm{CO}_{2}$. HiPerFect transfection reagent (Qiagen) was mixed with non-silencing siRNA or a mouse Fox/2 siRNA (Qiagen), incubated for $10 \mathrm{~min}$, and then added to cells for a final siRNA concentration of $5 \mathrm{nM}$, in accordance with the manufacturer's instructions. Two hours after transfection, cells were treated with either $50 \mu \mathrm{g} / \mathrm{ml} \mathrm{FSH}$ and $10 \mu \mathrm{g} / \mathrm{ml}$ testosterone or $50 \mu \mathrm{g} / \mathrm{ml} \mathrm{FSH}$ alone. Cells were continually cultured for $48 \mathrm{~h}$ and then lysed for RNA extraction. The transfection efficiency of siRNA was above $90 \%$, tested by Alexa Fluor 488 modified non-silencing siRNA (Qiagen).

\section{Lentiviral vector infection}

The mouse Fox/2 cDNA described earlier was subcloned into the VSVG-pseudotyped lentiviral vector (Gene Vector Core Laboratory, Diabetes and Endocrinology Research Center, Baylor College of Medicine, Houston, TX, USA). Mouse granulosa cells $\left(5 \times 10^{5} /\right.$ well in a six-well plate) were plated in culture medium containing $1 \mu \mathrm{l} / \mathrm{ml}$ Polybrene (hexadimethrine bromide, Sigma) and incubated at $37{ }^{\circ} \mathrm{C}$ with $5 \%$ $\mathrm{CO}_{2}$ for $2 \mathrm{~h}$. Twenty microliters of concentrated control or Fox/2 lentiviral vectors were then added to the cells. After 3 days of incubation, cells were then treated with $50 \mu \mathrm{g} / \mathrm{ml} \mathrm{FSH}$ and $10 \mu \mathrm{g} / \mathrm{ml}$ testosterone or $50 \mu \mathrm{g} / \mathrm{ml} \mathrm{FSH}$ alone. Cells were continually cultured for $48 \mathrm{~h}$ and then lysed for RNA extractions. The infection efficiency was around $80 \%$, determined by the percentage of GFP-positive cells for lentiviral constructs with GFP reporter. Multiplicity of infection (MOI) was around two, calculated according to the percentage of infected cells.

\section{Quantitative real-time PCR}

Total RNA was extracted from mouse granulosa cells using the RNeasy Mini Kit according to the manufacturer's protocol (Qiagen), and cDNA was synthesized from $1 \mu \mathrm{g}$ total RNA
Table 1 Primer sequences used for quantitative real-time PCR analyses.

\begin{tabular}{ll}
\hline Gene & Sequence $\left(5^{\prime}-3^{\prime}\right)$ \\
\hline Foxl2 & F: CGGCATCTACCAGTACATCATAGC \\
& R: GCACTCGTTGAGGCTGAGGTTG \\
Star & F: GACGTCGGAGCTCTCTGCTT \\
& R: GCCTTCTGCATAGCCACCTC \\
Cyp19a1 & F: ATGTTCTTGGAAATCTCAACCC \\
Cyp11a1 & R: AGGACCTGGTATTGAGACGAG \\
& F: TTACATCGTGGACCCCAAGG \\
Cond2 & R: CGGTCTTTCTTCCAGGCATC \\
Actb & F: GGTGCAGTGTGCATGTTCCT \\
& R: GCCAGGTTCACTTCAGCTT \\
& F: CATTGCTGACAGGATGCAGAAGGAG \\
& R: CCTGCTTGCTGATCCACATCTGCTG \\
\hline
\end{tabular}

using the iScript cDNA Synthesis kit (Bio-Rad Laboratories). To quantify the amounts of the transcripts present, $1 \mu \mathrm{RT}$ reaction was used in a $25 \mu \mathrm{l}$ q-RT-PCR reaction. Q-RT-PCR was performed on a MyiQ Thermal Cycler (Bio-Rad Laboratories) using iQ SYBR green supermix (Bio-Rad Laboratories) for 40 cycles in two-step reactions: $95^{\circ} \mathrm{C}$ for $10 \mathrm{~s}$ and $60{ }^{\circ} \mathrm{C}$ for 45 s. The primers for mouse Foxl2, Star, Cyp19a1, Cyp11a1, Ccnd2, and Actb were listed in Table 1. Gene expression levels were calculated by normalizing cycle numbers to those of Actb.

\section{Declaration of interest}

The authors declare that there is no conflict of interest that could be perceived as prejudicing the impartiality of the research reported.

\section{Funding}

This work was supported by R01HD047603 from the National Institute of Child Health and Human Development (NICHD) and the Office of Research on Women's Health (ORWH) (M D Pisarska) and by a grant from the Helping Hands of Los Angeles, Inc. (M D Pisarska).

\section{References}

Barnhart KM \& Mellon PL 1994 The orphan nuclear receptor, steroidogenic factor-1, regulates the glycoprotein hormone $\alpha$-subunit gene in pituitary gonadotropes. Molecular Endocrinology 8 878-885. (doi:10.1210/me.8. 7.878)

Benayoun BA, Auer J, Caburet S \& Veitia RA 2008a The post-translational modification profile of the forkhead transcription factor FOXL2 suggests the existence of parallel processive/concerted modification pathways. Proteomics 8 3118-3123. (doi:10.1002/pmic.200800084)

Benayoun BA, Caburet S, Dipietromaria A, Bailly-Bechet M, Batista F, Fellous M, Vaiman D \& Veitia RA 2008 $b$ The identification and characterization of a FOXL2 response element provides insights into the pathogenesis of mutant alleles. Human Molecular Genetics 17 3118-3127. (doi:10.1093/hmg/ddn209)

Benayoun BA, Caburet S, Dipietromaria A, Georges A, D'Haene B, Pandaranayaka PJ, L'Hote D, Todeschini AL, Krishnaswamy S, Fellous M et al. 2010 Functional exploration of the adult ovarian granulosa cell tumor-associated somatic FOXL2 mutation p.Cys134Trp (c.402C > G). PLoS ONE 5 e8789. (doi:10.1371/journal.pone.0008789)

Bentsi-Barnes IK, Kuo FT, Barlow GM \& Pisarska MD 2009 Human forkhead L2 represses key genes in granulosa cell differentiation including aromatase, P450scc, and cyclin D2. Fertility and Sterility 94 353-356. (doi:10.1016/j.fertnstert.2009.09.050) 
Bentsi-Barnes IK, Kuo FT, Barlow GM \& Pisarska MD 2010 Human forkhead L2 represses key genes in granulosa cell differentiation including aromatase, P450scc, and cyclin D2. Fertility and Sterility 94 353-356. (doi:10.1016/j.fertnstert.2009.09.050)

Blixt A, Mahlapuu M, Aitola M, Pelto-Huikko M, Enerback S \& Carlsson P 2000 A forkhead gene, FoxE3, is essential for lens epithelial proliferation and closure of the lens vesicle. Genes and Development 14 245-254. (doi:10.1101/gad.14.2.245)

Blount AL, Schmidt K, Justice NJ, Vale WW, Fischer WH \& Bilezikjian LM 2009 FoxL2 and Smad3 coordinately regulate follistatin gene transcription. Journal of Biological Chemistry 284 7631-7645. (doi:10.1074/jbc. M806676200)

Brissette JL, Li J, Kamimura J, Lee D \& Dotto GP 1996 The product of the mouse nude locus, Whn, regulates the balance between epithelial cell growth and differentiation. Genes and Development 10 2212-2221. (doi:10.1101/gad.10.17.2212)

Carlsson P \& Mahlapuu M 2002 Forkhead transcription factors: key players in development and metabolism. Developmental Biology 250 1-23. (doi:10.1006/dbio.2002.0780)

Clark BJ, Wells J, King SR \& Stocco DM 1994 The purification, cloning, and expression of a novel luteinizing hormone-induced mitochondrial protein in MA-10 mouse Leydig tumor cells. Characterization of the steroidogenic acute regulatory protein (StAR). Journal of Biological Chemistry 269 28314-28322.

Crisponi L, Deiana M, Loi A, Chiappe F, Uda M, Amati P, Bisceglia L, Zelante L, Nagaraja R, Porcu S et al. 2001 The putative forkhead transcription factor FOXL2 is mutated in blepharophimosis/ptosis/epicanthus inversus syndrome. Nature Genetics 27 159-166. (doi:10.1038/ 84781)

Dottori M, Gross MK, Labosky P \& Goulding M 2001 The winged-helix transcription factor Foxd3 suppresses interneuron differentiation and promotes neural crest cell fate. Development 128 4127-4138.

Fan HY, O'Connor A, Shitanaka M, Shimada M, Liu Z \& Richards JS 2010 $\beta$-Catenin (CTNNB1) promotes preovulatory follicular development but represses LH-mediated ovulation and luteinization. Molecular Endocrinology 24 1529-1542. (doi:10.1210/me.2010-0141)

Fitzpatrick SL \& Richards JS 1991 Regulation of cytochrome P450 aromatase messenger ribonucleic acid and activity by steroids and gonadotropins in rat granulosa cells. Endocrinology 129 1452-1462. (doi:10.1210/endo-129-3-1452)

Fleming NI, Knower KC, Lazarus KA, Fuller PJ, Simpson ER \& Clyne CD 2010 Aromatase is a direct target of FOXL2: C134W in granulosa cell tumors via a single highly conserved binding site in the ovarian specific promoter. PLOS ONE 5 e14389. (doi:10.1371/journal.pone.0014389)

Fraser IS, Shearman RP, Smith A \& Russell P 1988 An association among blepharophimosis, resistant ovary syndrome, and true premature menopause. Fertility and Sterility $\mathbf{5 0} 747-751$.

Gonzalez-Robayna IJ, Falender AE, Ochsner S, Firestone GL \& Richards JS 2000 Follicle-stimulating hormone (FSH) stimulates phosphorylation and activation of protein kinase $\mathrm{B}$ (PKB/Akt) and serum and glucocorticoidInduced kinase (Sgk): evidence for A kinase-independent signaling by FSH in granulosa cells. Molecular Endocrinology 14 1283-1300. (doi:10.1210/me.14.8.1283)

Hsueh AJ, Adashi EY, Jones PB \& Welsh TH Jr 1984 Hormonal regulation of the differentiation of cultured ovarian granulosa cells. Endocrine Reviews 5 76-127. (doi:10.1210/edrv-5-1-76)

Kaestner KH, Knochel W \& Martinez DE 2000 Unified nomenclature for the winged helix/forkhead transcription factors. Genes and Development 14 142-146. (doi:10.1101/gad.14.2.142)

Kashimada K, Svingen T, Feng CW, Pelosi E, Bagheri-Fam S, Harley VR, Schlessinger D, Bowles J \& Koopman P 2011 Antagonistic regulation of Cyp26b1 by transcription factors SOX9/SF1 and FOXL2 during gonadal development in mice. FASEB Journal 25 3561-3569. (doi:10.1096/fj.11184333)

Kaufmann E \& Knochel W 1996 Five years on the wings of fork head. Mechanisms of Development 57 3-20. (doi:10.1016/0925-4773 (96)00539-4)

Kaufmann E, Müller D \& Knöchel W 1995 DNA recognition site analysis of Xenopus winged helix proteins. Journal of Molecular Biology $\mathbf{2 4 8}$ 239-254. (doi:10.1016/S0022-2836(95)80047-6)
Kim SY, Weiss J, Tong M, Laronda MM, Lee EJ \& Jameson JL 2009 Foxl2, a forkhead transcription factor, modulates nonclassical activity of the estrogen receptor- $\alpha$. Endocrinology 150 5085-5093. (doi:10.1210/en. 2009-0313)

Kumar TR, Wang Y, Lu N \& Matzuk MM 1997 Follicle stimulating hormone is required for ovarian follicle maturation but not male fertility. Nature Genetics 15 201-204. (doi:10.1038/ng0297-201)

Kuo FT, Bentsi-Barnes IK, Barlow GM \& Pisarska MD 2011 Mutant forkhead L2 (FOXL2) proteins associated with premature ovarian failure (POF) dimerize with wild-type FOXL2, leading to altered regulation of genes associated with granulosa cell differentiation. Endocrinology 152 3917-3929. (doi:10.1210/en.2010-0989)

Lamba P, Fortin J, Tran S, Wang Y \& Bernard DJ 2009 A novel role for the forkhead transcription factor FOXL2 in activin A-regulated folliclestimulating hormone $\beta$ subunit transcription. Molecular Endocrinology 23 1001-1013. (doi:10.1210/me.2008-0324)

Lee K, Pisarska MD, Ko JJ, Kang Y, Yoon S, Ryou SM, Cha KY \& Bae J 2005 Transcriptional factor FOXL2 interacts with DP103 and induces apoptosis. Biochemical and Biophysical Research Communications 336 876-881. (doi:10.1016/j.bbrc.2005.08.184)

Lehmann OJ, Sowden JC, Carlsson P, Jordan T \& Bhattacharya SS 2003 Fox's in development and disease. Trends in Genetics 19 339-344. (doi:10.1016/S0168-9525(03)00111-2)

Lin D, Sugawara T, Strauss JF III, Clark BJ, Stocco DM, Saenger P, Rogol A \& Miller WL 1995 Role of steroidogenic acute regulatory protein in adrenal and gonadal steroidogenesis. Science 267 1828-1831. (doi:10.1126/ science.7892608)

Liu YX \& Hsueh AJ 1986 Synergism between granulosa and thecainterstitial cells in estrogen biosynthesis by gonadotropin-treated rat ovaries: studies on the two-cell, two-gonadotropin hypothesis using steroid antisera. Biology of Reproduction 35 27-36. (doi:10.1095/ biolreprod35.1.27)

Liu Z, Rudd MD, Hernandez-Gonzalez I, Gonzalez-Robayna I, Fan H-Y, Zeleznik AJ \& Richards JS 2009 FSH and FOXO1 regulate genes in the sterol/steroid and lipid biosynthetic pathways in granulosa cells. Molecular Endocrinology 23 649-661. (doi:10.1210/me.2008-0412)

Marongiu M, Deiana M, Meloni A, Marcia L, Puddu A, Cao A, Schlessinger D \& Crisponi L 2010 The forkhead transcription factor Foxl2 is sumoylated in both human and mouse: sumoylation affects its stability, localization, and activity. PLOS ONE 5 e9477. (doi:10.1371/ journal.pone.0009477)

Moons DS, Jirawatnotai S, Tsutsui T, Franks R, Parlow AF, Hales DB, Gibori G, Fazleabas AT \& Kiyokawa H 2002 Intact follicular maturation and defective luteal function in mice deficient for cyclin- dependent kinase-4. Endocrinology 143 647-654. (doi:10.1210/en.143.2.647)

Nakae J, Kitamura T, Kitamura Y, Biggs WH III, Arden KC \& Accili D 2003 The forkhead transcription factor Foxo1 regulates adipocyte differentiation. Developmental Cell 4 119-129. (doi:10.1016/S15345807(02)00401-X)

Nishi Y, Yanase T, Mu Y, Oba K, Ichino I, Saito M, Nomura M, Mukasa C, Okabe T, Goto K et al. 2001 Establishment and characterization of a steroidogenic human granulosa-like tumor cell line, KGN, that expresses functional follicle-stimulating hormone receptor. Endocrinology 142 437-445. (doi:10.1210/en.142.1.437)

Overdier DG, Porcella A \& Costa RH 1994 The DNA-binding specificity of the hepatocyte nuclear factor $3 /$ forkhead domain is influenced by aminoacid residues adjacent to the recognition helix. Molecular and Cellular Biology 14 2755-2766. (doi:10.1128/MCB.14.4.2755)

Park Y, Maizels ET, Feiger ZJ, Alam H, Peters CA, Woodruff TK, Unterman TG, Lee EJ, Jameson JL \& Hunzicker-Dunn M 2005 Induction of cyclin D2 in rat granulosa cells requires FSH-dependent relief from FOXO1 repression coupled with positive signals from Smad. Journal of Biological Chemistry 280 9135-9148. (doi:10.1074/jbc.M409486200)

Park M, Shin E, Won M, Kim JH, Go H, Kim HL, Ko JJ, Lee K \& Bae J 2010 FOXL2 interacts with steroidogenic factor-1 (SF-1) and represses SF-1-induced CYP17 transcription in granulosa cells. Molecular Endocrinology 24 1024-1036. (doi:10.1210/me.2009-0375)

Pierrou S, Hellqvist M, Samuelsson L, Enerbäck S \& Carlsson P 1994 Cloning and characterization of seven human forkhead proteins: binding site specificity and DNA bending. EMBO Journal 13 5002-5012. 
Pisarska MD, Bae J, Klein C \& Hsueh AJ 2004 Forkhead I2 is expressed in the ovary and represses the promoter activity of the steroidogenic acute regulatory gene. Endocrinology 145 3424-3433. (doi:10.1210/en. 2003-1141)

Pisarska MD, Kuo FT, Bentsi-Barnes IK, Khan S \& Barlow GM 2010 LATS1 phosphorylates forkhead L2 and regulates its transcriptional activity. American Journal of Physiology. Endocrinology and Metabolism 299 E101-E109. (doi:10.1152/ajpendo.00534.2009)

Pisarska MD, Barlow G \& Kuo FT 2011 Minireview: roles of the forkhead transcription factor FOXL2 in granulosa cell biology and pathology. Endocrinology 152 1199-1208. (doi:10.1210/en.2010-1041)

Richards JS 1994 Hormonal control of gene expression in the ovary. Endocrine Reviews 15 725-751. (doi:10.1210/edrv-15-6-725)

Richards IS \& Pangas SA 2010 The ovary: basic biology and clinical implications. Journal of Clinical Investigation 120 963-972. (doi:10.1172/JCl41350)

Richards JS, Russell DL, Robker RL, Dajee M \& Alliston TN 1998 Molecular mechanisms of ovulation and luteinization. Molecular and Cellular Endocrinology 145 47-54. (doi:10.1016/S0303-7207(98)00168-3)

Roux J, Pictet R \& Grange T 1995 Hepatocyte nuclear factor 3 determines the amplitude of the glucocorticoid response of the rat tyrosine aminotransferase gene. DNA and Cell Biology 14 385-396. (doi:10. 1089/dna.1995.14.385)

Schmidt D, Ovitt CE, Anlag K, Fehsenfeld S, Gredsted L, Treier AC \& Treier M 2004 The murine winged-helix transcription factor Foxl2 is required for granulosa cell differentiation and ovary maintenance. Development 131 933-942. (doi:10.1242/dev.00969)

Shah SP, Kobel M, Senz J, Morin RD, Clarke BA, Wiegand KC, Leung G, Zayed A, Mehl E, Kalloger SE et al. 2009 Mutation of FOXL2 in granulosa-cell tumors of the ovary. New England Journal of Medicine 360 2719-2729. (doi:10.1056/NEJMoa0902542)

Sicinski P, Donaher JL, Geng Y, Parker SB, Gardner H, Park MY, Robker RL, Richards JS, McGinnis LK, Biggers JD et al. 1996 Cyclin D2 is an FSHresponsive gene involved in gonadal cell proliferation and oncogenesis. Nature 384 470-474. (doi:10.1038/384470a0)

Stocco DM 2001 StAR protein and the regulation of steroid hormone biosynthesis. Annual Review of Physiology 63 193-213. (doi:10.1146/ annurev.physiol.63.1.193)

Uda M, Ottolenghi C, Crisponi L, Garcia JE, Deiana M, Kimber W, Forabosco A, Cao A, Schlessinger D \& Pilia G 2004 Foxl2 disruption causes mouse ovarian failure by pervasive blockage of follicle development. Human Molecular Genetics 13 1171-1181. (doi:10.1093/ hmg/ddh124)

Ueda H, Sun GC, Murata T \& Hirose S 1992 A novel DNA-binding motif abuts the zinc finger domain of insect nuclear hormone receptor FTZ-F1 and mouse embryonal long terminal repeat-binding protein. Molecular and Cellular Biology 12 5667-5672. (doi:10.1128/MCB.12. 12.5667)

Uhlenhaut NH, Jakob S, Anlag K, Eisenberger T, Sekido R, Kress J, Treier AC, Klugmann C, Klasen C, Holter NI et al. 2009 Somatic sex reprogramming of adult ovaries to testes by FOXL2 ablation. Cell 139 1130-1142. (doi:10.1016/j.cell.2009.11.021)

Wang DS, Kobayashi T, Zhou LY, Paul-Prasanth B, Ijiri S, Sakai F, Okubo K, Morohashi K \& Nagahama Y 2007 Foxl2 up-regulates aromatase gene transcription in a female-specific manner by binding to the promoter as well as interacting with ad4 binding protein/steroidogenic factor 1. Molecular Endocrinology 21 712-725. (doi:10.1210/ me.2006-0248)

Wayne CM, Fan HY, Cheng X \& Richards JS 2007 Folliclestimulating hormone induces multiple signaling cascades: evidence that activation of Rous sarcoma oncogene, RAS, and the epidermal growth factor receptor are critical for granulosa cell differentiation. Molecular Endocrinology 21 1940-1957. (doi:10.1210/me. 2007-0020)

Zhou L, Dey CR, Wert SE, Yan C, Costa RH \& Whitsett JA 1997 Hepatocyte nuclear factor-3 $\beta$ limits cellular diversity in the developing respiratory epithelium and alters lung morphogenesis in vivo. Developmental Dynamics 210 305-314. (doi:10.1002/(SICI)1097-0177(199711)210: $3<305:$ :AID-AJA10>3.0.CO;2-9)

Zlotogora J, Sagi M \& Cohen T 1983 The blepharophimosis, ptosis, and epicanthus inversus syndrome: delineation of two types. American Journal of Human Genetics 35 1020-1027.

Received 18 July 2011

First decision 15 August 2011

Revised manuscript received 13 July 2012

Accepted 27 July 2012 